\title{
Betaherpesvirus (Cmv, Hhv-6 and Hhv-7) Active Infections in Brazilian Hematopoietic Stem Cell Transplant Patients
}

\author{
Sandra HA Bonon ${ }^{1}$, Daniela Corte Parola ${ }^{1}$, Ronaldo Luis Thomasini ${ }^{1}$, Bruna Maria Roesler ${ }^{1}$, José P.Aranha ${ }^{2}$, Cármino A.De Souza ${ }^{2}$, Afonso \\ C.Vigorito ${ }^{2}$ and Sandra C.B.Costa ${ }^{1 *}$
}

${ }^{1}$ Department of Internal Medicine, Faculty of Medical Sciences, State University of Campinas (UNICAMP), CP 6111, CEP 13081-970, Campinas, São Paulo, Brazil ${ }^{2}$ Bone Marrow Transplant Unit, Hemocenter, Faculty of Medical Sciences, State University of Campinas (UNICAMP), CP 6111, CEP 13081-970, Campinas, São Paulo, Brazil

\begin{abstract}
Cytomegalovirus (CMV) is one of the most prevalent infectious pathogen in transplant recipients, including those receiving bone marrow or stem cell grafts. Rapid diagnostic tests to identify active CMV infection and preemptive treatment are significant improvements in the management of CMV. Two newly identified beta herpesviruses, human herpesvirus-6 (HHV-6) and human betaherpesvirus-7 (HHV-7), are genetically more closely related to each other than to CMV and have been frequently detected in the blood of allogeneic HSCT. HHV-6 reactivation has been associated with fever, rash, delayed engraftment and encephalitis. Also, HHV-7 has been reported as a cause of severe central nervous system disease and with severe GVHD and sepsis secondary to immune suppression. Nested polymerase chain reaction in blood samples (serum or leukocytes) was used to monitor active CMV, HHV-6 and HHV-7 infections and disease in forty-three HSCT patients for up to 150 days after transplant. All adult recipients with a risk for $C M V$ disease ( $D+/ R+; D+/ R-)$ were enrolled in this study. Acyclovir was used at low doses prior to the transplant as herpes virus prophylactic therapy. Patients who were at least 2 consecutive N-PCR positive for CMV received preemptive therapy with ganciclovir. The prevalence's of positive active CMV, HHV-6 and HHV-7 infections were $72 \%, 4.6 \%$ and $13.9 \%$, respectively. Thirteen patients died $(30.2 \%)$. Biopsies confirmed CMV disease occurred in 8 out of 43 patients $(18.6 \%)$, in the gastrointestinal tract. All of them presented active CMV infection and one presented active CMV+HHV-6 infection. None of these patients presented active HHV-7 infection. One patient with CMV disease died by disseminated CMV. Detection of active HHV-6 and HHV-7 infections was low and clinically significant complications were rare. CMV disease remains the most prominent disease associated with HSCT. Results show that surveillance with N-PCR - a sensitive, non-invasive and low-cost technique for detection of active beta herpesvirus infections - can be used when antigenemia or DNA quantitative methods are unavailable, because patients with a propensity for developing CMV disease can be readily identified and pre-emptive therapy started.
\end{abstract}

Keywords: Cytomegalovirus; HHV-6; HHV-7; Nested-PCR; Hematopoietic stem cell transplantation

\section{Introduction}

The human $\beta$-herpesviruses - cytomegalovirus (CMV), HHV-6 and HHV-7, are ubiquitous viruses that infect the majority of humans. Primary infections with these viruses in the immunocompetent host are characterized by a benign clinical course. CMV causes an infectious mononucleosis-like syndrome while HHV-6 and HHV-7 cause roseola infantum, febrile seizures and other febrile syndromes in children $[1,2]$.

The characteristically persistent nature of these infections allows reactivation with numerous clinical consequences during periods of immune suppression such as those occurring after organ or bone marrow transplantation. CMV has long been recognized as a significant source of morbidity and mortality in allogeneic bone marrow transplant patients and in this setting can manifest as pneumonitis, gastrointestinal syndromes, hepatitis, bone marrow suppression, and occasionally retinitis $[3,4]$.

Ganciclovir has been established as an effective prophylactic agent for CMV infection [5]. Because of the high mortality rate associated with CMV, antiviral prophylaxis and/or preemptive therapy have been widely used after hematopoietic stem cell transplantation (HSCT) while improved diagnostic methods and correct deployment of antiviral chemotherapy against CMV has dramatically reduced the incidence of CMV pneumonitis in hematology patients which has also led to improved outcomes in infected patients [4].
Human herpesvirus 6 (HHV-6) and HHV-7, first discovered in 1986 and 1990, respectively, are genetically related to human cytomegalovirus (CMV) and as such are grouped with the latter in the betaherpesvirinae subfamily. Two variants of HHV-6 have been defined (termed HHV-6A and HHV-6B). HHV-7 is detectable in a variety of transplant settins, both HSCT and solid organ. Direct effects include fever, rash, myelossupression, encephalitis, and pneumonitis. Potentially, more important are the indirect effects HHV-7 has on CMV disease, invasive fungal disease and allograft dysfunction [6,7].

In this study, we examined the impact of detection of active infection by $\beta$-herpesvirus (CMV, HHV-6 and HHV-7) in HSCT patients after transplantation using a simple and reliable method: a Nested-polymerase chain reaction (Nested-PCR) technique after

${ }^{*}$ Corresponding author: Sandra C.B.Costa, Department of Internal Medicine, Faculty of Medical Sciences, State University of Campinas (UNICAMP), CP 6111, CEP 13081-970, Campinas, São Paulo, Brazil. Tel.:+ 5519 3521-7734; Fax: +55 19 3289-4107; E-mail: costa@fcm.unicamp.br

Received November 01, 2011; Accepted November 24, 2011; Published November 28, 2011

Citation: Bonon SHA, Parola DC, Thomasini RL, Roesler BM, Aranha JP, et al (2011) Betaherpesvirus (Cmv, Hhv-6 and Hhv-7) Active Infections in Brazilian Hematopoietic Stem Cell Transplant Patients. J Bioanal Biomed S4: 001 doi:10.4172/1948-593X.S4-001

Copyright: (c) 2011 Bonon SHA, et al. This is an open-access article distributed under the terms of the Creative Commons Attribution License, which permits unrestricted use, distribution, and reproduction in any medium, provided the original author and source are credited. 
Citation: Bonon SHA, Parola DC, Thomasini RL, Roesler BM, Aranha JP, et al. (2011) Betaherpesvirus (Cmv, Hhv-6 and Hhv-7) Active Infections in Brazilian Hematopoietic Stem Cell Transplant Patients. J Bioanal Biomed S4: 001. doi:10.4172/1948-593X.S4-001

transplant in samples of blood (leukocytes and/or serum) from patients monitored until day 150 .

\section{Materials and Methods}

Forty-three myeloablative hematopoietic stem cell transplant recipients with HLA identical siblings were selected from the Bone Marrow Transplant (BMT) unit of the university hospital. Patients requiring allogeneic hematopoietic stem cell transplantation for a variety of conditions were monitored prospectively for active CMV, HHV-6 and HHV-7 infections from 2004 to 2006, using NestedPCR. The patients did not receive CMV hyper immunoglobulin. The blood products used were neither screened for CMV antibody nor filtered to deplete leukocytes, although all had been irradiated. Conditioning regimens and acute GVHD prophylaxis were selected based on ongoing protocols. Acute graft versus host disease (GVHD) was graded according to published criteria [8]. All patients received GVHD prophylaxis with cyclosporine (CSP) and methotrexate (MTX), and were tested for underlying diseases using established institutional protocols. Low doses of Acyclovir prophylaxis were used to prevent herpes virus simplex infections prior to engraftment. Patient's characteristics are shown in Table 1.

The patients were monitored in the 150 days following transplantation. Blood was collected weekly for N-PCR. The protocol was designed in accordance with the requirements for research involving human subjects in Brazil, and was approved by the Institutional Ethics Committee.

Leukocyte and Serum DNA extraction Briefly, DNA was extracted from 200ul of serum or "buffy-coat" using a phenol-chloroform protocol after overnight incubation in lysis buffer (containing SDS and proteinase $\mathrm{K}$ ) at $56^{\circ} \mathrm{C}$ which was followed by DNA precipitation with cold ethanol [9]. The resulting DNA pellet was eluted in 50ul of TEbuffer.

\begin{tabular}{|l|l|}
\hline Characteristic & $(\mathrm{n}=43)$ \\
\hline Age - Median years (range) & $38(22-63)$ \\
\hline Sex - Male/Female & $23 / 20$ \\
\hline Underlying disease $-n$ (\%) & \\
\hline Malignant disease & \\
\hline Acute lymphocytic leukemia (ALL) & $3(6.9)$ \\
\hline Acute myelogenous leukemia (AML) & $8(18.6)$ \\
\hline Chronic myelogenous leukemia (CML) & $18(41.9)$ \\
\hline Multiple Myeloma (MM) & $6(14)$ \\
\hline \multicolumn{1}{|c|}{ Non-Hodgkin Lymphoma (NHL) } & $2(4.65)$ \\
\hline Severe aplastic anaemia (SAA) & $3(6.9)$ \\
\hline Others & $3(6.9)$ \\
\hline Pretransplant CMV serostatus $-n(\%)$ & \\
\hline R+/D+ & $39(90.7)$ \\
\hline R-/D+ & $4(9.3)$ \\
\hline Stem cell source & $17(39.5)$ \\
\hline Bone marrow & $26(60.5)$ \\
\hline Peripheral blood & \\
\hline
\end{tabular}

Table 1: Patients' characteristics.
Nested polymerase chain reaction (N-PCR) CMV, HHV-6 and HHV-7 DNA in blood specimens were detected by an Nested-PCR technique using primers described by Demmler et al.[10];Shibata et al. [11]; Secchiero et al. [12] and Pozo et al. [13]. The sizes of the Nested-PCR amplification products were 159, 258 and 122 base pairs, respectively. The same protocol was used to amplify the human $\beta$-globin gene sequence to guarantee the quality of the extracted DNA. All experiments had two negative controls (one without DNA and the other with a human PBL DNA preparation known to be negative for CMV DNA) and one positive control (by CMV strain AD169 aliquot).

\section{Definitions}

Active CMV infection: Active CMV infection was defined based on the following criteria: two or more positive Nested-PCR CMV-DNA results detected in leukocytes

CMV disease: The detection of active infection had to be accompanied by clinical symptoms and histopathological identification of CMV [14].

Active HHV-6 infection: Active HHV-6 infection was defined based on the following criteria: one or more positive Nested-PCR HHV-6-DNA result from serum-extracted DNA [15].

Active HHV-7 infection: Active HHV-7 infection was defined based on the following criteria: one or more positive Nested-PCR HHV-7-DNA result from serum-extracted DNA [16,17].

\section{Treatment of active CMV infection}

Patients with proven active CMV infection received ganciclovir (5 $\left.\mathrm{mg} / \mathrm{kg}, i . v_{\text {. }}\right)$, twice a day for 7 days followed by a maintenance dose of 5 $\mathrm{mg} / \mathrm{kg} /$ day, i.v., three times a week for 4 weeks. Preemptive therapy was discontinued only after the end of the maintenance dose and if active CMV infection was not detectable.

\section{Treatment of CMV disease}

CMV disease was treated with ganciclovir ( $5 \mathrm{mg} / \mathrm{kg}$, i.v.), twice a day for 21 days, followed by a maintenance dose of $5 \mathrm{mg} / \mathrm{kg} /$ day, i.v., three times a week for 4 weeks if active CMV infection was not detectable.

\section{Statistical analysis}

All data were analyzed using the Fisher Exact test [18]. AP value of $<0.05$ indicated statistical significance. All statistical analysis was performed using Graph Pad software.

\section{Results}

\section{Diagnosis of active CMV, HHV-6 and HHV-7 infections and co-infections after transplantation}

Thirty-one patients $(72 \%)$ had active CMV infection in two or more leukocyte samples during the monitoring period. First, positivity occurred at a median of 65 days (range 0-160 days) after transplant. HHV-6 analyzed in serum, variant B, was detected in $2 / 43$ patients (4.6\%) at a median of 43 days after transplant (range 0-154 days). Active HHV-7 infection was detected in serum in 6/43 patients (13.9\%) and occurred at a median of 47 days after transplant (range 0-140).

Detection of HHV-6 infection occurred first (median 43 days), followed by HHV-7 (median 47 days) and CMV (median 65 days) after HSCT. 
Citation: Bonon SHA, Parola DC, Thomasini RL, Roesler BM, Aranha JP, et al. (2011) Betaherpesvirus (Cmv, Hhv-6 and Hhv-7) Active Infections in Brazilian Hematopoietic Stem Cell Transplant Patients. J Bioanal Biomed S4: 001. doi:10.4172/1948-593X.S4-001

Page 3 of 6

Co-infections CMV+HHV-6 occurred in $2 / 43$ (4.6\%) and CMV+HHV-7 occurred in 4/43 (9.3\%) patients. These infected patients are summarized in (Table 2).

\section{Acute GVHD and betaherpesvirus infections}

Of the 43 subjects, the incidence of grades I-IV acute GVHD (aGVHD) was 51\% (22/43). Fifteen out of twenty-two these patients had active CMV infection (68\%); one had active HHV-6 infection (4.5\%) and three patients with aGVHD had active HHV-7 infection (13.6\%). No statistical significance was found by Fisher's exact test in relation to active betaherpesvirus infections and occurrence of GVHD (Table 3).

\section{Opportunistic infections and betaherpesvirus infections and co-infections}

Sixteen out of thirty one (51.6\%) patients with active CMV infection had opportunist infections. Infections by bacteria and fungi were statistically significant in relation to active CMV infection $(\mathrm{p}=0.001)$ (Table 4).

\section{Risk factors for the development of CMV disease}

Statistically significant risk factors for CMV disease found in these patients were the occurrence of active CMV infection which was detected by N-PCR $(\mathrm{p}=0.02)$ and the prevalence of opportunistic infection, which was due to bacteria or fungi $(\mathrm{p}=0.001)$.

\section{Recipient-donor serostatus relationship and active CMV infection and disease}

When the data for active CMV infection and disease were analyzed in terms of CMV antibody serostatus for patients prior to HSCT, 29 out of 43 active CMV seropositive patients developed active CMV infection (67.4\%). All patients with CMV disease were CMV-IgG seropositive patients. Two out of four seronegative patients had CMV infection, but

\begin{tabular}{|l|l|l|}
\hline & N=43 & GVHD \\
\hline Patients, n (\%) & $43(100 \%)$ & $22 / 43(51 \%)$ \\
\hline $\begin{array}{l}\text { Positive N-PCR } \\
\text { Median time - days (range) }\end{array}$ & $\begin{array}{l}31 / 43(72 \%) \\
65(0-160)\end{array}$ & $15 / 22(68 \%)$ \\
\hline $\begin{array}{l}\text { Positive N-PCR - HHV-6 in serum (\%) } \\
\text { Median time - days (range) }\end{array}$ & $\begin{array}{l}2 / 43(4.6 \%) \\
\mathbf{4 3 ( 0 - 1 5 4 )}\end{array}$ & $1 / 22(4.5 \%)$ \\
\hline $\begin{array}{l}\text { Positive N-PCR - HHV-7 in serum (\%) } \\
\text { Median time - days (range) }\end{array}$ & $\begin{array}{l}6 / 43(13.9 \%) \\
\mathbf{4 7}(0-140)\end{array}$ & $3 / 22(13.6 \%)$ \\
\hline Co-infection CMV+HHV-6 & $2 / 43(4.6 \%)$ & - \\
\hline Co-infection CMV+HHV-7 & $4 / 43(9.3 \%)$ & - \\
\hline
\end{tabular}

${ }^{*} \mathrm{~N}-\mathrm{PCR}$ - nested-PCR

Table 2: Prevalence of active CMV, HHV-6 and HHV-7 infections and co-infections and occurrence of GVHD.

\begin{tabular}{|l|l|l|l|}
\hline \multicolumn{2}{|l|}{ Acute GVHD } & \multirow{2}{*}{$\boldsymbol{p}^{*}$} \\
\hline Active Infection & Presence & Absence & \\
\hline CMV & $15 / 22$ & $13 / 21$ & 0.45 \\
\hline$H H V-6$ & $1 / 22$ & $1 / 21$ & 0.74 \\
\hline$H H V-7$ & $3 / 22$ & $3 / 21$ & 0.64 \\
\hline
\end{tabular}

*Fisher's exact test

Table 3: Incidence of grades I-IV aGVHD and active CMV, HHV-6 and HHV-7 infections.

\begin{tabular}{|l|l|l|l|}
\hline & \multicolumn{2}{|l|}{ Opportunistic Infection } & $\boldsymbol{p}^{*}$ \\
\hline Active Infection & Presence & Absence & \\
\hline CMV & $16 / 16$ & $15 / 27$ & $\mathbf{0 . 0 0 1}$ \\
\hline$H H V-6$ & $0 / 16$ & $0 / 27$ & 1.0 \\
\hline HHV-7 & $1 / 16$ & $0 / 27$ & 0.37 \\
\hline CMV+HHV6 & $0 / 16$ & $0 / 27$ & 1.0 \\
\hline CMV+HHV-7 & $1 / 16$ & $0 / 27$ & 0.37 \\
\hline
\end{tabular}

${ }^{*}$ Fisher's exact test

Table 4: Cases of active CMV, HHV-6 and HHV-7 infections and cobetaherpesvirus infections and opportunistic infection.

\begin{tabular}{|l|l|l|l|l|}
\hline $\begin{array}{l}\text { CMV } \\
\text { serostatus }\end{array}$ & $\begin{array}{l}\text { Active CMV } \\
\text { infection } \\
\mathbf{n}(\%)\end{array}$ & $\begin{array}{l}\text { Active HHV-6 } \\
\text { infection } \\
\mathbf{n}(\%)\end{array}$ & $\begin{array}{l}\text { Active HHV-7 } \\
\text { infection } \\
\mathbf{n}(\%)\end{array}$ & $\begin{array}{l}\text { CMV disease } \\
\mathbf{n}(\%)\end{array}$ \\
\hline R+/D+ & $29(67.4)$ & $2(4.6)$ & $5(11)$ & $8(18.6)$ \\
\hline R-/D+ & $2(4.6)$ & - & $1(2.3)$ & - \\
\hline Total & 31 & 2 & 6 & 8 \\
\hline
\end{tabular}

Table 5: Recipient (R) and donor (D) CMV serostatus and outcome (active CMV, HHV-6 and HHV-7 infection and CMV disease) following allogeneic hematopoietic stem cell transplantation.

no disease occurred. One of these patients had active HHV-7 infection. Table 5 shows the prevalence of active CMV, HHV-6 and HHV-7 infections and CMV disease based on CMV donor/recipient serostatus.

\section{Prevalence of CMV disease}

Eight out of 43 patients (18.6\%) developed CMV disease, which occurred in a median of 47 days (range 24-64) after the transplant. These patients presented CMV gastrointestinal (GI) disease, which was proven with gastrointestinal tract biopsy specimens. All patients were treated with ganciclovir, but one of them died due to disseminated CMV disease. All eight patients who developed CMV disease were CMV seropositive allogeneic HSCT recipients and seven patients had acute GVHD.

CMV-DNA detected by N-PCR became positive at the same time as the development of CMV disease with a median time of 47 days (range 0-64 days). Nested-PCR for HHV-6 occurred in one patient with CMV disease at a median of 154 days. No patient with CMV disease presented active HHV-7 infection (Table 6).

\section{Characteristics of patients with CMV disease}

Patient $5(\mathrm{D}+/ \mathrm{R}+)$, CML. Showed N-PCR positive for DNA-CMV in 47 days after the transplant. N-PCR for HHV-6 and HHV-7 was negative. Symptoms of fever and nausea in day 47. A skin biopsy was done (oral cavity), diagnosing GVHD. Patient developed CMV disease with biopsy-proven TGI from day +144 . Received treatment with ganciclovir. Died of GVHD on day +189 .

Patient $6(\mathrm{D}+/ \mathrm{R}+)$, NHL. Presented fever and vomiting on day +63 and continued to demonstrate symptoms until day +142 . N-PCR for CMV became positive on the day of the onset of symptoms (+63). Received treatment with ganciclovir. N-PCR for HHV-6 and HHV-7 was negative. Mouth and skin biopsies diagnosing acute GVHD were performed. Colonoscopy showed mild inflammatory process consistent with GVHD. A necrosis of the stomach showed CMV in biopsy on day +119 . Died on day +157 of disseminated CMV disease and GVHD. 
Citation: Bonon SHA, Parola DC, Thomasini RL, Roesler BM, Aranha JP, et al. (2011) Betaherpesvirus (Cmv, Hhv-6 and Hhv-7) Active Infections in Brazilian Hematopoietic Stem Cell Transplant Patients. J Bioanal Biomed S4: 001. doi:10.4172/1948-593X.S4-001

Page 4 of 6

\begin{tabular}{|c|c|c|c|c|c|c|c|c|}
\hline \multirow[b]{2}{*}{$\mathbf{n}$} & \multirow[b]{2}{*}{ Status D/R } & \multirow[b]{2}{*}{ Underlying disease } & \multirow[b]{2}{*}{ Disease } & \multicolumn{5}{|c|}{ Days after transplant } \\
\hline & & & & Symptoms & $\begin{array}{l}\text { CMV } \\
\text { N-PCR+ }\end{array}$ & $\begin{array}{l}\text { HHV-6 } \\
\text { N-PCR+ }\end{array}$ & $\begin{array}{l}\text { HHV-7 } \\
\text { N-PCR+ }\end{array}$ & $\begin{array}{l}\text { GIT Biopsy } \\
\text { positive for } \\
\text { CMV }\end{array}$ \\
\hline 5 & $R+/ D+$ & $\mathrm{CML}^{*}$ & GIT & 47 & 47 & - & - & 144 \\
\hline 6 & $\mathrm{R}+/ \mathrm{D}+$ & $\mathrm{NHL}^{*}$ & GIT† & 63 & 63 & - & - & 119 \\
\hline 8 & $R+/ D+$ & $\mathrm{AML}^{*}$ & GIT & 54 & 54 & - & - & 40 \\
\hline 18 & $R+/ D+$ & $\mathrm{CML}^{*}$ & GIT & 0 & 26 & - & - & 69 \\
\hline 21 & $R+/ D+$ & $\mathrm{AML}^{*}$ & GIT & 29 & 40 & - & - & 36 \\
\hline 22 & R+/D+ & CML & GIT & 36 & 47 & - & - & 114 \\
\hline 25 & $R+/ D+$ & $\mathrm{MM}^{*}$ & GIT & 64 & 64 & 154 & - & 160 \\
\hline \multirow[t]{2}{*}{33} & $R+/ D+$ & $\mathrm{CML}^{*}$ & GIT & 59 & 24 & - & - & 145 \\
\hline & \multicolumn{3}{|c|}{ Median days (range) } & $47(0-64)$ & $47(24-64)$ & 154 & - & 114 \\
\hline
\end{tabular}

D/R - donor/recipient; GIT - gastrointestinal tract (gastritis); N-PCR+ - positive nested polymerase chain reaction; * - patients with acute GVHD; $†$ - died by disseminated CMV disease.

Table 6: Clinical and laboratory features of CMV disease.

Patient $8(\mathrm{D}+/ \mathrm{R}+)$, AML. Diagnosed with CMV disease in biopsyproven TGI on day +40 . N-PCR positive for CMV on day +54 , without symptoms. Received treatment with ganciclovir. Biopsy fragment of oral mucosa was consistent with GVHD.

Patient $18(\mathrm{D}+/ \mathrm{R}+)$, CML. Presented fever of unknown origin on the day ooof transplantation which lasted until day +69 . N-PCR positive for CMV on day +26 . Received treatment with ganciclovir. Biopsies of the esophagus and stomach were performed on day +26 without changes in GVHD. Patient developed CMV disease in the gastrointestinal tract (GIT), which was confirmed by biopsy on day +69 . Died on day +85 by acute respiratory insufficiency of unknown etiology.

Patient $21(\mathrm{D}+/ \mathrm{R}+)$, AML. Presented diarrhea and high fever on day +29 . N-PCR positive for CMV from day +40 until day +143 . Biopsies: salivary gland on +134 (compatible with acute GVHD), liver on day +143 (acute hepatitis with hepatocellular necrosis), esophagus and stomach on +42 (compatible with GVHD). Patient developed CMV disease in the gastrointestinal tract (GIT), which was confirmed by biopsy on day +36 . Received treatment with ganciclovir.

Patient $22(\mathrm{D}+/ \mathrm{R}+)$, CML. Presented symptoms of diarrhea and vomiting on day +36 and N-PCR positive for HCMV from day +47 until day +82 . Patient developed CMV disease in the gastrointestinal tract (GIT), which was confirmed by biopsy on day +114 . Received treatment with ganciclovir.

Patient $25(\mathrm{D}+/ \mathrm{R}+), \mathrm{MM}$. Presented fever and diarrhea on day +64 , while maintaining the clinical picture until day +170 . N-PCR for CMV became positive on the day of the onset of symptoms $(+64)$. Presented active HHV-6 infection on day +154 . Received treatment with ganciclovir. Biopsies: Skin, mouth and gut on day +93 (diagnosing GVHD), and repeat biopsies on day +141 (also diagnosing the presence of GVHD). Patient developed CMV disease in biopsy-proven TGI on day +160 .

Patient $33(\mathrm{D}+/ \mathrm{R}+)$, CML. Presented fever, weight loss, vomiting and diarrhea on day +59 . N-PCR for HCMV became positive on day +24 , which continued until day +145 . Received treatment with ganciclovir. Gastric biopsies were performed (diagnosing GVHD) and liver (inconclusive). CMV disease progressed with TGI biopsyproven. Death on day +157 by hypovolemic shock and cardiac arrest unspecified.

\section{Discussion}

This study was performed on a group of patients who underwent bone marrow or stem cell transplantation and was the first to be performed in Brazil to analyze post transplant betaherpesvirus infections in hematopoietic stem cell transplantation patients using Nested-PCR. Surveillance started on the day of the transplant and continued for the following 150 days, with samples blood collected weekly to detect active betaherpesvirus infections. The monitoring active CMV infection using Nested-PCR and antigenemia was performed in our laboratotory in transplant patients to trigger preemptive therapy. This protocol has been used with success in immunocompromised patients from Clinics Hospital, University of Campinas [19].

In order to increase the monitoring of these patients in relation to other active herpesvirus infections like as HHV-6 and HHV-7, it was decided to verify the presence of these viruses, the clinical impact they cause, and the correlation with active CMV infection in a group of HSCT patients $(\mathrm{n}=43)$ using N-PCR assay.

In this group of patients, the high prevalence of active CMV infection (72\%) detected by N-PCR was comparable to our previous reports on HSCT $[19,20]$. Although the proportion of CMV seronegative donors/ recipients was small, almost all of the positive N-PCR tests were from CMV seropositive patients.

CMV is one of the most feared infectious complications following hematopoietic stem cell transplantation. Many risk factors for CMV disease have been defined in prospective studies; active CMV infection is associated with an increased risk of developing of CMV disease post HSCT. These studies used conventional cell culture and rapid culture methods, such as shell vial culture and the detection of early antigen fluorescent foci (DEAFF) test [4]. Subsequently, the detection of the virus using more sensitive methods, such as antigenemia and the polymerase chain reaction (PCR), has confirmed that the presence of active CMV infection in blood is a risk factor for CMV disease [21-23].

Cytomegalovirus (CMV) disease has historically been a main cause of death after allogeneic hematopoietic stem cell transplantation (HSCT). Since the introduction of prophylactic and/or preemptive therapy against CMV, the incidence of CMV disease has successfully 
Citation: Bonon SHA, Parola DC, Thomasini RL, Roesler BM, Aranha JP, et al. (2011) Betaherpesvirus (Cmv, Hhv-6 and Hhv-7) Active Infections in Brazilian Hematopoietic Stem Cell Transplant Patients. J Bioanal Biomed S4: 001. doi:10.4172/1948-593X.S4-001

been reduced. However, breakthrough CMV disease, particularly CMV gastrointestinal disease, remains one of the major infectious complications. Administration of the antiviral agent, ganciclovir, is often associated with myelotoxicity in HSCT recipients and delays immune reconstitution against CMV [24].

In our work, the organ most commonly affected with CMV disease was the gastrointestinal tract, as reported in other studies $[3,24]$ and nowadays is a main problem in allogeneic hematopoietic stem cell transplantation.

Laboratorial surveillance indicated that all patients with CMV disease were detected early on but, despite preventive therapy, the overall prevalence of CMV disease was $18.6 \%$ in this study. This is comparable to recently reported prevalences of 0 to $16 \%$ [25].

All patients with CMV disease in our work had at least one of the known risk factors for CMV disease, such as active CMV infection, which was statistically significant $(\mathrm{p}=0.02)$.

CMV is considered an immune modulatory virus and has been shown to facilitate super infections with opportunistic infections. CMV-induced impairment of T-helper cells, macrophage and are the proposed basis for this immunosuppressive effect [26]. We found in this work that the occurrence of opportunistic infections and active CMV infection was statistically significant $(\mathrm{p}=0.001)$.

While the positive predictive value of detecting HHV-6 DNA with PCR for clinically significant disease may be uncertain, a negative result may be good evidence for excluding HHV-6 aetiology. This hypothesis has been shown to be valid for CMV but requires confirmation for HHV6. In HSCT recipients, detection of viral DNA in the plasma correlated with disease attributable to the virus. However, the sensitivity of HHV6 DNA detection in plasma for diagnosis of clinically significant HHV6 disease in HSCT patients is unknown [27].

Acute GVHD is a serious problem during a disease caused by $\mathrm{CMV}$, despite antiviral therapy. HHV-6 reactivation has been linked to the increased severity of graft-versus-host-disease, as well as a delay or suppression of myeloengraftment in HSCT [28].

In the present molecular surveillance study, low prevalence of active HHV-6 and HHV-7 infections was observed in $4.6 \%$ and $13.9 \%$, respectively in contrast to reported study [29]. Although the differences in prevalence among studies could be accounted for by patient characteristics and the lack of a standardized assay, it is also reasonable to hypothesize that the low prevalence of HHV-6 and HHV-7 DNA emia in the present study may be related to the use of antiviral prophylaxis with Acyclovir to prevent herpes virus simplex infection before the engraftment.

Many questions remain with regards to these viruses (HHV-6 and HHV-7); a full understanding of the clinical impact of these viruses is required which must include direct effects, interactions with CMV, and other immunomodulatory effects. In patients with symptoms directly attributable to one of these viruses, treatment may be initiated with ganciclovir along with a reduction in immunossupression [28].

Further investigation of the clinical significance of HHV-6 and HHV-7 DNAemia is necessary.

\section{Conclusion}

The contribution of HHV-6 and HHV-7 to illness in HSCT recipients has not been fully elucidated, but the evidence is mounting that these viruses may cause substantial illness. The clinical syndrome needs sharper definition, and the relationship between these viruses and "CMV disease" needs additional studies. Our results demonstrate that the surveillance with Nested-PCR for detection of active CMV, HHV-6 and HHV-7 infections can be very usefull in patients with a propensity for developing CMV disease. These infections can be readily identified and preemptive therapy instituted.

\section{Acknowledgements}

The authors thank Erin Elizabeth O'Connor, a native English teacher, fo revising English

\section{References}

1. Black JB, Pellett PE (1999) Human herpesvirus 7. Rev Med Virol 9: 245-262.

2. Clark DA (2000) Human herpesvirus 6. Rev Med Virol 10: 155-173.

3. Reusser P (1996) The challenge of cytomegalovirus infection after Bone Marrow Transplantation: Epidemiology, Prophylaxis, and Therapy. Bone Marrow Transplant 18: 107-109.

4. 4.Clark DA, Emery VC, Griffiths PD (2003) Cytomegalovirus, Human Herpesvirus-6, and Human Herpesvirus-7 in Hematological Patents. Seminars in Hematol 40: 154-162.

5. Winston DJ, Winston GH, Kathy Bartony RN, Ebeling DF, Buhles WC, et al (1993) Ganciclovir prophylaxis of Cytomegalovirus Infection and Disease in Allogeneic Bone Marrow Transplant recipients. Ann Intern Med 118: 179-184.

6. de Pagter PJ, Schuurman R, Maijer E, van Baarle D, Sanders EA, et al (2008) Human herpesvirus type 6 reactivation after haematopoietic stem cell transplantation. J Clin Virol 43: 361-366

7. Boutolleau D, Fernandez C, André E, Imbert-Marcille BM, Milpied N, et al (2003) Human herpesvirus (HHV)-6 and HHV-7: two closely related viruses with different infection profiles in stem cell transplantation recipients. J Infec Dis 187: $179-186$

8. Przepiorka D, Weisdorf D, Martin P, Klingemann HG, Beatty P, et al. (1995) Consensus conference on acute GVHD grading. Bone Marrow Transpl 15 825-828.

9. Hudnall D, Chen T, Allison P, Tyring S, Heath A (2008) Herpesvirus prevalence and viral load in healthy blood donors by quantitative real-time polymerase chain reaction. Transfusion 48: 1180-1187.

10. Demmler GJ, Buffone GJ, Schimbor CM, May RA, et al. (1988) Detection of Cytomegalovirus in Urine from Newborns by using Polymerase Chain Reaction DNA Amplification. J Infect Dis 158: 1177-1184.

11. Shibata, D, Martin WJ, Appleman MD, Causey DM, Leedom JM, et al. (1988) Detection of Cytomegalovirus DNA in Peripheral Blood of Patients Infected with Human Immunodeficiency Virus. J Infect Dis 158: 1185-1192.

12. Secchiero P, Carrigan DR, Asano Y, Benedetti L, Crowley RW, et al. (1995) Detection of Human Herpesvirus 6 in plasma of Children with Primary Infection and Immunossupressed Patients by Polymerase Chain Reaction. J Infect Dis 171: $273-280$.

13. Pozo F, Tenorio A (1999) Detection and typing of lymphotropic herpesviruses by multiplex polymerase chain reaction. J Virol Methods 79: 9-19.

14. Ljungman P, Plotkin SA (1995) Workshop on CMV Disease; Definition, Clinica Severity Scores, and New Syndromes. Scand J Infect Dis 99: 87-89.

15. Costa FA, Soki MN, Andrade PD, Bonon SHA, Thomasini RL, et al. (2011) Simultaneous monitoring of CMV and human herpesvirus 6 infections and diseases in liver transplant patients: one year follow-up. Clinics 66: 949-953.

16. Thomasini RL, Martins JMM, Parola DC, Bonon SHA, Boin IFSF, et al. (2008) Detection of human herpesvirus-7 by qualitative nested-PCR: comparison between healthy individuals and liver transplant recipients. Rev Soc Bras Med Trop 41: 556-559.

17. Peigo MF, Thomasini RL, Puglia ALP, Costa SHA, Bonon SHA, et al. (2009) Human herpesvirus-7 in Brazilian liver transplant recipients: a follow-up 
Citation: Bonon SHA, Parola DC, Thomasini RL, Roesler BM, Aranha JP, et al. (2011) Betaherpesvirus (Cmv, Hhv-6 and Hhv-7) Active Infections in Brazilian Hematopoietic Stem Cell Transplant Patients. J Bioanal Biomed S4: 001. doi:10.4172/1948-593X.S4-001

Page 6 of 6

comparison between molecular and immunological assays. Transpl Infect Dis 11: 497-502

18. Agresti A (1992) A Survey of Exact Inference for Contegency Tables, Statitical Science 7:131-153.

19. Bonon SHA, Menoni SMF, Rossi CL, De Souza CA, Vigorito AC, et al. (2005) Surveillance of cytoemaglovirus infection in haematopoietic stem cell transplantation patients. J Infection 50: 130-137.

20. Peres RM, Costa CR, Andrade PD, Bonon SH, Albuquerque DM, et al. (2010) Surveillance of active human cytomegalovirus infection in hematopoietic stem cell transplantation (HLA sibling identical donor): search for optimal cutoff value by real-time PCR. BMC Infect Dis 10:147.

21. Baldanti F, Revello MG, Percivalle E, Gerna G (1998) Use of the human cytomegalovirus (HCMV) antigenemia assay for diagnosis and monitoring of HSCM infections and detection of antiviral drug resistance in the immunocompromised. J Clin Virol 11: 51-60.

22. Einsele H, Steidle M, Vallbracht A, Saal JG, Ehninger G, et al. (1991) Early concurrence of human cytomegalovirus infection after bone marrow transplantation as demonstrated by the polymerase chain reaction technique. Blood 11: 1104-1110.

23. Tanaka Y, Kanda Y, Kami M, Mori S, Hamaki T, et al. (2002) Monitoring cytomegalovirus infection by antigenemia assay and two distinct plasma real- time PCR methods after hematopoietic stem cell transplantation. Bone Marrow Transplant 30: 315-319.

24. Mori T, Kato J (2010) Cytomegalovirus infection/disease after hematopoietic stem cell transplantation. Int J Hematol 91: 588-595.

25. Machado CM, Menezes RX, Macedo MCA, Mendes AV, Boas LS, et al. (2001) Extended antigenemia surveillance and late cytomegalovirus infection after allogeneic BMT. Bone Marrow Transplant 28: 1053-1059.

26. Nina Singh, Cheryl Wannstedt, Lois Keyes, Wagener MM, Gayowski T, et al (2005) Indirect Outcomes Associated with Cytomegalovirus (Opportunistic Infections, Hepatitis C Virus Sequelae , and Mortality) in Liver-Transplant Recipients with the Use of Preemptive Therapy for 13 Years. Transplantation 79: 1428-1434.

27. Peiris M (1999) Human herpesvirus-6 (HHV-6) and HHV-7 infections in bone marrow transplant recipients. Clinical Reviews in Oncology/Hematology 32: 187-196.

28. Ljungman $P$ (2002) Prevention and treatment of viral infections in stem cel transplant recipients. $\mathrm{Br} \mathrm{J}$ Haematol 118: 44-57.

29. Machado CM, Menezes RX, Macedo MCA, Mendes AV, Boas LS, et al. (2001) Extended antigenemia surveillance and late cytomegalovirus infection after allogeneic BMT. Bone Marrow Transplant 28: 1053-1059.
This article was originally published in a special issue, Hematopoietic Stem Cell Transplantation handled by Editor(s). Dr. Utpal Sen, University of Louisville, USA 